\title{
Self-reported conflict management competence among nursing students on the point of graduating and registered nurses with professional experience
}

\author{
Janeth Leksell ${ }^{* 1}$, Ann Gardulf ${ }^{2,3}$, Jan Nilsson ${ }^{3,4}$, Margret Lepp $p^{5,6}$ \\ ${ }^{1}$ The School of Education, Health and Social Studies, Dalarna University, Falun, Sweden \\ ${ }^{2}$ Department of Laboratory Medicine, Karolinska Institutet at Karolinska University Hospital, Huddinge, Stockholm, Sweden \\ ${ }^{3}$ The Japanese Red Cross Institute for Humanitarian Studies, Tokyo, Japan \\ ${ }^{4}$ The Department of Health Sciences, Faculty of Health, Science, and Technology, Karlstad University, Karlstad, Sweden \\ ${ }^{5}$ The Institute of Health and Care Science, University of Gothenburg, Gothenburg, Sweden \\ ${ }^{6} \varnothing$ stfold University College, Halden, Norway
}

Received: March 29, 2015

DOI: $10.5430 /$ jnep.v5n8p82
Accepted: May 10, 2015

Online Published: May 27, 2015

\begin{abstract}
Objective: It has been shown that specific competence is necessary for preventing and managing conflicts in healthcare settings. The aim of this descriptive and correlation study was to investigate and compare the self-reported conflict management competence (CMC) of nursing students who were on the point of graduating (NSPGs), and the CMC of registered nurses (RNs) with professional experience.

Methods: The data collection, which consisted of soliciting answers to items measuring CMC in the Nurse Professional Competence (NPC) Scale, was performed as a purposive selection of 11 higher education institutions (HEIs) in Sweden. Three CMC items from the NPC Scale were answered by a total of 569 nursing students who were on the point of graduating and 227 $\mathrm{RN}$ registered nurses with professional experience.

Results: No significant differences between NSPGs and RNs were found, and both groups showed a similar score pattern, with the lowest score for the item: "How do you perceive your ability to develop the group and strengthen competence in conflict management and problem-solving, based on knowledge of group dynamics?". RNs with long professional experience ( $>24$ months) rated their overall CMC as significantly better than RNs with short ( $<24$ months) professional experience did ( $p=.05$ ). NSPGs who had experience of international studies during their nursing education reported higher CMC, compared with those who did not have this experience $(p=.03)$. RNs who reported a high degree of utilisation of CMC during the previous month scored higher regarding self-reported overall CMC $(p<.0001)$.

Conclusions: Experience of international studies during nursing education, or long professional experience, resulted in higher self-reported CMC. Hence, the CMC items in the NPC Scale can be suitable for identifying self-reported conflict management competence among NSPGs and RNs.
\end{abstract}

Key Words: Conflicts, Conflict management, Self-reported, Registered nurses, Nursing students

${ }^{*}$ Correspondence: Janeth Leksell; Email: jle@du.se; Address: The School of Education, Health and Social Studies, Dalarna University, Högskolan Dalarna, Sweden. 


\section{INTRODUCTION}

The ability to manage conflict is a necessary competence for functioning effectively as a registered nurse. ${ }^{[1,2]}$ In nursing education, attention should therefore be focused on conflict management ability, in order to deal with the often complex practice of healthcare. ${ }^{[3,4]}$

\subsection{Background}

\subsubsection{Definition of conflict}

There is no uniform definition of the concept of conflict, but conflicts are always present within the individual, between individuals and within an organisation; ${ }^{[5]}$ and healthcare settings are no exception to this. A conflict can be defined as a disagreement in which the parties involved perceive a threat to their needs, interests or concerns. ${ }^{[6]}$ As pointed out by de Wit and colleagues ${ }^{[7]}$ and Johansen, ${ }^{[6]}$ more research is needed to understand the relationships between different types of conflicts, conflict strategies and group outcomes.

In a meta-analysis from 2012, de Wit and colleagues divided the concept of conflict into three parts: relationship-related, task-related, and process-related. ${ }^{[7]}$ Relationship-related conflicts involve disagreement among group members, such as differences of opinion regarding norms and values; taskrelated conflicts involve disagreement among group members about the content and outcomes of the task being performed; whereas process-related conflicts involve disagreement about the logistics of job achievement, such as the delegation of tasks and responsibilities.

Different conflict strategies, so-called situational conflict management, can be used in different situations, but little is known about which strategies are optimal for handling different types of conflict. ${ }^{[6]}$ Poorly managed conflict and unresolved conflicts in healthcare settings have a negative influence on individuals, organisations and, most importantly, on patient outcome. ${ }^{[6]}$

\subsubsection{CMC and nursing}

The concept of conflict management is the process of limiting the negative aspects of a conflict while increasing its positive aspects. ${ }^{[5]}$ The aim of conflict management is to enhance learning and group outcomes, including performance in organisational settings. ${ }^{[5]}$ Registered Nurses (RNs) play an important role regarding conflict management within healthcare settings. ${ }^{[4]}$ The registered nurse is often the leader of a multidisciplinary healthcare team, and should therefore have the knowledge and skills to manage conflict efficiently and effectively. Successful conflict management results in improved quality of care, patient safety and staff morale, as well as reduced work stress for caregivers and enhances knowledge regarding conflict management is enhanced. ${ }^{[6]}$
Conflict management concerns the de-escalation of conflict. ${ }^{[3]}$ Research within this area has often focused on the concept of conflict management style. ${ }^{[2,7,8]}$ Conflict management styles are complex, and we may use one style more than others. However, the style we use depends on the situation and the participants involved in a particular conflict. One instrument, the Thomas-Kilmann Conflict Mode Instrument (TKI), has shown satisfactory validity and reliability, and has been used widely in studies on conflict management in healthcare. ${ }^{[9-12]}$ The TKI consists of the following subscales, i.e. coping styles: competing, accommodating, avoiding, collaborating and compromising. ${ }^{[12]}$ Few studies have documented the outcome of interventions tailored to manage conflict. Furthermore, a recently published intervention pilot study, using simulated training with different scenarios, showed little or no significant change in conflict management. ${ }^{[10]}$ The authors highlighted the difficult task of enabling learning among nursing students, with regard to managing conflict. It is obvious that more studies are needed in order to examine how best to empower students, so that they are able to manage in situations where they are confronted with real-world conflict.

In a review, Pearson ${ }^{[13]}$ emphasised the responsibility of registered nurses for creating a healthy work environment; this is stressed as essential in preventing and managing conflict. Flexibility, trust, respect, support, consideration and motivation are mentioned in the review as being some of the characteristics of a leader that seem to be most important for a healthier work environment. Other important aspects highlighted are that leaders should be knowledgeable and qualified, as well as supportive and encouraging with regard to the professional growth of their staff. Communication is a recurrent theme in the literature; leaders who communicated effectively and involved their staff in the decision-making process were seen as being involved in creating a healthy work environment. It seems obvious that a constructive style or approach facilitates the prevention of work where management of conflict is necessary. ${ }^{[3,13]}$

In Sweden, nursing education is a three-year Bachelor programme that leads to a professional qualification as a registered nurse and a bachelor's degree in nursing. The education is influenced by the competence requirements established by the Swedish National Board of Health and Welfare, with conflict management representing one of the important competences that a registered nurse is required to have. ${ }^{[14]} \mathrm{RNs}$ need to learn about conflict and conflict management strategies in order to address and manage conflict effectively. ${ }^{[8,10]}$ By learning strategies for conflict management they are empowered to resolve and prevent conflict early on, and influence the work environment where they deliver patient 
care. ${ }^{[8,10]}$ According to Johansen, ${ }^{[6]}$ the registered nurse manager is a central actor in making a difference for patients and their families, as well as staff.

Findings from earlier research on this topic indicate that it seems necessary to have the competence to prevent conflicts in healthcare settings wherever possible, and otherwise to be able to manage them if they occur. We conclude that such competence should include knowledge of group dynamics, skills in problem-solving and motivation, as well as involving staff in the decision-making process.

\subsection{Aim}

The main aim of this descriptive and correlation study was to investigate and compare the self-reported CMC of nursing students who were on the point of graduating(NSPGs), and the $\mathrm{CMC}$ of registered nurses with professional experience. A further aim was to compare self-reported conflict management and international experience among nursing students and registered nurses. A third aim was to investigate the self-reported conflict management of registered nurses, with respect to the length of their professional experience and their utilisation of conflict management.

\section{MAterials AND MethodS}

\subsection{Data collection and sample}

The data collection consisted of soliciting answers to the Nurse Professional Competence (NPC) Scale, ${ }^{[14]}$ and was performed as a purposive selection of NSPGs and RNs from a total of 11 higher education institutions (HEIs) in Sweden.

For NSPGs, data were collected during the last week of the three-year university-level nursing programme at the 11 HEIs.

For RNs with professional experience, data were collected during the first week of the RNs' specialist nursing education (January 2012-January 2013) at five HEIs. The specialist nursing education the RNs had begun was in the field of operating care, public healthcare, pre-hospital care or elderly care.

NSPGs and the RNs were asked to participate in the study by answering the NPC Scale, including items addressing conflict management competence. A total of 569 NSPGs and 227 RNs answered the NPC Scale, resulting in a response rate of $77 \%$ among the NSPGs and $71 \%$ among the RNs.

Table 1. Sociodemographic data for nursing students who were on the point of graduating and registered nurses

\begin{tabular}{|c|c|c|c|c|}
\hline Characteristics & $\begin{array}{l}\text { Nursing students } \\
(\mathrm{N}=569)\end{array}$ & $\begin{array}{l}\text { Registered nurses } \\
(\mathrm{N}=227)\end{array}$ & $\begin{array}{l}\text { Total } \\
(\mathrm{N}=769)\end{array}$ & $p$ \\
\hline Age, mean (min-max) & $27.6(6.3)$ & $36.8(8.7)$ & 30.2 & .00 \\
\hline \multicolumn{5}{|l|}{ Sex } \\
\hline Women & 86.4 & 88.9 & 87.1 & .20 \\
\hline Men & 13.6 & 11.1 & 12.9 & \\
\hline \multicolumn{5}{|l|}{ Living situation } \\
\hline Living alone & 29.7 & 19.9 & 26.8 & .00 \\
\hline Living in a relation & 70.6 & 80.1 & 73.2 & \\
\hline \multicolumn{5}{|l|}{ Having children < age 18 (\%) } \\
\hline Yes & 27.1 & 54.2 & 34.8 & .00 \\
\hline No & 72.9 & 45.8 & 65.2 & \\
\hline \multicolumn{5}{|l|}{ Upper secondary school (\%) } \\
\hline Natural Science & 22.9 & & & \\
\hline Nursing & 15.3 & & & \\
\hline Social Science & 31.2 & & & \\
\hline Other & 30.6 & & & \\
\hline University studies prior to nursing education (\%) & 34.9 & & & \\
\hline Experience of international studies prior to nursing education (\%) & 58.1 & & & \\
\hline $\begin{array}{l}\text { Paid work experience in healthcare alongside the Bachelor } \\
\text { programme during nursing education (\%) }\end{array}$ & 69.7 & & & \\
\hline \multicolumn{5}{|l|}{ Shift work (\%) } \\
\hline Day & & 77.9 & & \\
\hline Night & & 10.2 & & \\
\hline Day and night & & 11.9 & & \\
\hline Experience of international studies (\%) & 10 & 21.0 & & \\
\hline
\end{tabular}


In addition to the NPC Scale, background socio-demographic data were included (see Table 1). The table shows that the NSPGs were significantly younger than the RNs $(p=.00)$, and the proportions of women and men were similar in the two groups ( $86.4 \%$ and $88.9 \%$ women, ns). Further details regarding socio-demographic data are presented in Table 1.

\subsection{Measures}

\subsubsection{The NPC scale}

The NPC Scale ${ }^{[14]}$ is based on formal national competence requirements. It consists of 88 items asking about self-reported ability to perform different competence requirements. The items are formulated as questions, e.g., "How do you perceive your ability to motivate the team and to provide constructive feedback?" with the following response options: to a very low degree $=1$; to a relatively low degree $=2$; to a relatively high degree $=3$; and to a very high degree $=4$. The NPC Scale distributed to the RNs included an additional question on each competence item, asking how often this competence had been used in the past month. The response options were: never (1); seldom (2); sometimes (3); and often (4). The scale has been evaluated for psychometric properties and has shown satisfactory data quality and validity. ${ }^{[14]}$

\subsubsection{Procedure for selecting CMC items}

The research team read through all the items in the NPC Scale and selected those that were appropriate in relation to earlier research regarding CMC. Initially six items were selected; thereafter, the six items were tested in a correlation analysis, which finally resulted in three items (CMC: 72-74), with Cronbach's alpha $0.69(0.4-0.46 ; p=.00)$. Subsequently, the following three NPC items measuring conflict management competence were used in this study, for both NSPGs and RNs:

How do you perceive your ability to:

- develop the group and strengthen competence in conflict management and problem-solving, based on knowledge of group dynamics?

- motivate the team and provide constructive feedback?

- utilise co-worker/staff views and suggestions for developing and improving care?

The RNs also answered the additional question: "How often during the past month have you practised your competence in conflict management?" reflecting reported competence in managing conflicts during the previous month. A new item, "Total CMC", was created by pooling the three CMC items. Cronbach's alpha for the new pooled variable was 0.69 for both NSPGs and RNs, and was considered to reflect overall, self-reported conflict management ability.

Published by Sciedu Press

\subsection{Statistical analyses}

Statistical analyses were performed using SPSS for Windows, version 20 (SPSS Inc., Chicago, IL, USA). Descriptive analysis was used for nominal variables. The chi-square test was applied on categorical variables, and independent t-test and Anova were used for interval data. Each item was transformed into a score of 1 to 100 , with 100 indicating a very high degree of CMC.

\subsection{Ethical considerations}

According to current Swedish law on research ethics, approval from the Ethics Committee is not required for this kind of study, since no identifiable data are collected in the questionnaires used. ${ }^{[15]}$ Participants' contributions to the study were based on voluntary participation after their informed consent had been obtained. A written enquiry was sent to the principals at the 11 HEIs, and all the principals gave their permission to perform the study. Potential respondents were informed about the study. By filling in the questionnaire, the participating NSPGs were considered to have given their informed consent to participate in the study. The questionnaire was answered anonymously.

\section{RESULTS}

Answers to the three CMC items were analysed, and will be presented under the following four headings:

(1) Self-reported conflict management competence: comparison between nursing students and registered nurses;

(2) Self-reported conflict management competence with respect to length of professional experience among registered nurses;

(3) Self-reported conflict management competence with respect to international experience among nursing students and registered nurses;

(4) Utilisation of self-reported conflict management competence among registered nurses.

\subsection{Self-reported CMC: comparison between nursing students and registered nurses}

Table 2 shows that NSPGs and RNs revealed a similar pattern regarding self-reported CMC, i.e. a lowest self-reported mean score for "How do you perceive your ability to develop the group and strengthen competence in conflict management and problem-solving, based on knowledge of group dynamics?" In one of the three questions, "How do you perceive your ability to utilise co-worker/staff views and suggestions for developing and improving care?", the NSPGs reported a higher numerical score than the RNs, although the difference did not reach a significant level $(p=.07)$. In the other two 
questions, the ratings of NSPGs were slightly higher than those of the RNs, although there was no significant difference. The mean scores for the overall CMC question were 75.83 and 74.24, respectively (n.s.). No differences were found in the NPC Scale regarding socio-demographic variables, apart from one exception: NSPGs who lived alone scored higher for the overall CMC question, compared with those living in a relation $(p=.01)$ (see Table 3$)$.

\subsection{Self-reported CMC with respect to length of profes- sional experience among registered nurses}

A significant difference regarding self-reported overall conflict management competence was found between RNs with short (1-24 months) vs. long (25-480 months) professional experience (70.70 vs. 75.23; $p=.05$ ) (see Table 2). Both groups scored highest (74.59 and 79.97) on the following question: "How do you perceive your ability to motivate the team and provide constructive feedback?" (CMC: 73), and lowest (63.46 and 66.64) on the question: "How do you perceive your ability to develop the group and strengthen competence in conflict management and problem-solving, based on knowledge of group dynamics?" (CMC: 72).
3.3 Self-reported Conflict Management Competence with respect to international experience among nursing students and registered nurses

Among the NSPGs, it was found that those with experience of international studies during their nursing education estimated that they had a higher degree of competence in managing conflicts, compared with those who did not have this experience (79.20 vs. 75.37; $p=.03$ ) (see Table 3). In contrast, there was no difference regarding reported conflict management competence among registered nurses with and without international work experience (76.92 vs. 73.62).

\subsection{Utilisation of CMC among registered nurses}

The RNs were divided into two groups, based on whether they had used their competence in conflict management (utilisation) in the past month to a high or low degree (see Table 3 ). RNs reporting a high degree of utilisation of conflict management competence scored higher on the items regarding overall CMC, than those reporting a low degree of utilisation of conflict management competence during the previous month $(77.84$ vs. $65.25 ; p<.00)$.

Table 2. Comparison of self-reported competence in conflict management between nursing students and registered nurses, and between registered nurses with short (1-24 months) versus long (25-480 months) professional experience

\begin{tabular}{|c|c|c|c|c|}
\hline CMC in nursing & Nursing students $(\mathrm{n}=569)$ & Registered nurses $(n=227)$ & \multirow{2}{*}{$p$} & \multirow{2}{*}{$t$} \\
\hline & Mean* (SD) & Mean* (SD) & & \\
\hline CMC 72 & $67.70(16.47)$ & $65.80(17.85)$ & .15 & -1.4 \\
\hline CMC 73 & $79.41(13.68)$ & $78.75(17.00)$ & .56 & -0.6 \\
\hline CMC 74 & $80.37(14.94)$ & $78.17(17.80)$ & .07 & -1.8 \\
\hline \multirow[t]{3}{*}{ CMC Total } & $75.83(12.40)$ & $74.24(13.68)$ & .09 & -1.6 \\
\hline & $\begin{array}{l}\text { Registered nurses } \\
\text { Professional experience } 1-24 \text { months }^{\dagger} \\
n=43\end{array}$ & $\begin{array}{l}\text { Registered nurses } \\
\text { Work experience } 25-480 \text { months }^{\dagger} \\
n=173\end{array}$ & & \\
\hline & Mean* (SD) & Mean* (SD) & & \\
\hline CMC 72 & $63.46(17.04)$ & $66.64(18.15)$ & .30 &.-1.3 \\
\hline CMC 73 & $74.59(18.51)$ & $79.97(16.53)$ & .06 &.-1.9 \\
\hline CMC 74 & 74.05 (16.36) & $79.10(17.82)$ & .09 & -1.7 \\
\hline CMC Total & $70.70(13.61)$ & $75.23(13.54)$ & .05 & -2.0 \\
\hline
\end{tabular}

Note. CMC = Conflict Management Competence; $*$ The results of the CMC scores are presented with values ranging from 1 to 100 , where a score of 100 indicates a very high degree of self-reported conflict competence management; ${ }^{\dagger}$ Classified according to Benner’s categorisation; i.e., novice, advanced beginner and competent equals 1-24 months, and proficient and expert equals 25- 480 months.

\section{Discussion}

The results of the analysis of the CMC items from the NPC Scale showed that NSPGs and RNs reported their CMC in a similar manner. However, the NSPGs' ratings were slightly higher than those of RNs, although there was no significant difference in any of the items. Nursing students, who had completed part of their studies abroad, estimated that they had higher conflict management competence than those who had no experience of international studies. Regarding RNs, those with and without experience of international work did not differ in any of the items. RNs with long work experience as nurses reported higher overall conflict competence 
than RNs with shorter professional experience. Furthermore, In addition, the questions regarding knowledge of group dythose who reported that they had used their expertise in con- namics and the ability to perform problem-solving, as well flict management competence during the past month scored as the importance of managing conflict, were rated lower higher on the questions compared with those who had not. than those about motivation and utilisation of knowledge.

Table 3. Distribution of NPC Scale mean score among the sample of nursing students and registered nurses by their competence management competence (CMC) status

\begin{tabular}{|c|c|c|c|c|c|}
\hline \multirow{2}{*}{ Background factors } & & \multicolumn{2}{|l|}{ CMC Nursing students } & \multicolumn{2}{|c|}{ CMC Registered nurses } \\
\hline & & Mean (SD) (n = 569) & $p$ & Mean (SD) $(n=227)$ & $p$ \\
\hline All & & $75.83(12.40)$ & & 74.24 (13.69) & .09 \\
\hline \multirow{2}{*}{ Sex } & Women & $76.00(12.30)$ & \multirow{2}{*}{.30} & $74.80(13.36)$ & \multirow{2}{*}{.08} \\
\hline & Men & $74.37(13.00)$ & & $70.00(15.96)$ & \\
\hline \multirow{4}{*}{ Age } & 21-27 years & $75.99(12.18)$ & \multirow{4}{*}{.68} & & \multirow{4}{*}{.13} \\
\hline & 28-50 years & $75.54(12.82)$ & & & \\
\hline & 20-37 years & & & $72.16(11.78)$ & \\
\hline & 38-65 years & & & $75.68(15.42)$ & \\
\hline \multirow{2}{*}{ Living situation } & Living alone & 78.12 (12.39) & \multirow{2}{*}{.01} & $71.36(14.13)$ & \multirow{2}{*}{.42} \\
\hline & Living in a relation & $75.15(12.24)$ & & $75.88(12.69)$ & \\
\hline \multirow{2}{*}{ Having children } & Yes & $75.37(11.46)$ & \multirow{2}{*}{.57} & $74.42(13.94)$ & \multirow[t]{2}{*}{.23} \\
\hline & No & $76.00(12.76)$ & & $74.01(13.40)$ & \\
\hline \multirow{4}{*}{ Upper Secondary School } & Natural Science & 75.25 (12.79) & \multirow{4}{*}{.29} & & \\
\hline & Nursing & $78.21(12.74)$ & & & \\
\hline & Social Science & $75.46(11.65)$ & & & \\
\hline & Other & $75.49(12.61)$ & & & \\
\hline \multirow{2}{*}{$\begin{array}{l}\text { University studies } \\
\text { prior to nursing education }\end{array}$} & Yes & $76.21(12.97)$ & \multirow[t]{2}{*}{.59} & & \\
\hline & No & $75.60(12.14)$ & & & \\
\hline \multirow{2}{*}{$\begin{array}{l}\text { University studies after } \\
\text { graduation }\end{array}$} & Yes & & & $74.30(13.56)$ & \multirow{2}{*}{.18} \\
\hline & No & & & $77.71(19.60)$ & \\
\hline \multirow{2}{*}{$\begin{array}{l}\text { Work experience in healthcare } \\
\text { prior to nursing education }\end{array}$} & Yes & $75.98(12.16)$ & \multirow{2}{*}{.73} & & \\
\hline & No & $75.61(12.60)$ & & & \\
\hline \multirow{2}{*}{$\begin{array}{l}\text { Work experience in healthcare } \\
\text { during nursing education }\end{array}$} & Yes & $75.88(12.53)$ & \multirow{2}{*}{.87} & & \\
\hline & No & $75.70(12.14)$ & & & \\
\hline \multirow{2}{*}{$\begin{array}{l}\text { Experience of international } \\
\text { studies during nursing education }\end{array}$} & Yes & $79.20(11.29)$ & \multirow{2}{*}{.03} & & \\
\hline & No & $75.37(12.44)$ & & & \\
\hline & Yes & & & $76.92(12.30)$ & $\Delta 6$ \\
\hline International work experience & No & & & $73.62(13.94)$ & .46 \\
\hline & Day & & & $74.90(13.58)$ & \\
\hline Shift work & Night & & & 74.79 (12.07) & .34 \\
\hline & Day and night & & & $70.00(13.67)$ & \\
\hline Work experience as RN & $1-24$ months $(n=43)$ & & & $70.70(13.61)$ & 05 \\
\hline Work experience as RN & 25-480 months $(\mathrm{n}=173)$ & & & & .05 \\
\hline RNs' utilisation of CMC during & Low $(n=59)$ & & & $65.25(14.91)$ & 00 \\
\hline the previous month & High $(n=162)$ & & & $77.84(12.02)$ & .00 \\
\hline & County & & & $74.87(13.75)$ & \\
\hline Employer & Municipality & & & $72.16(12.45)$ & .20 \\
\hline & State/Private/other & & & 69.39 (13.63) & \\
\hline
\end{tabular}

* The results of the CMC scores are presented with values ranging from 1 to 100 , where a score of 100 indicates a very high degree of self-reported competence. 
It may be questioned whether nursing students overestimated their ability to manage conflicts. However, in a review it was found that nursing students, or recent nursing graduates, often lacked knowledge in the following areas: communication, leadership, organisation, critical thinking, specific situations, and stress management. ${ }^{[2]}$ These competences are in line with questions used in our study. One possible explanation for why nursing students and registered nurses rated their competence in management of conflict in a similar way could be that nursing students have theoretical competence in managing conflict and believe that this will stand them in good stead for the future. On the other hand, we cannot know whether participants overestimated their competence, as there is no cutoff value. The questionnaire is not constructed in such a way that makes it possible to achieve such a cutoff value. In order to do this we would need to study the phenomenon further, for example through interviews and observation. This value could weed out those with very low levels of ability; on the other hand, there is no strong evidence that higher scores are associated with actual skills in conflict management.

Another interesting result from our study was that nursing students who had undertaken international studies rated their competence in conflict management as high. In an earlier study, we have shown that at graduation, nursing students with experience of international studies report high self-rated professional competence, measured with the NPC Scale. ${ }^{[14,16]}$ We also know from clinical experience that nursing students with international experience express a higher competence in several areas within nursing. One explanation for this can be found in a literature review identifying professional and personal development, and a greater understanding of healthcare provision in other countries, among nursing students undertaking international placements. ${ }^{[17]}$ The experience of good international studies might improve the emotional capacity to deal with conflicts. High emotional capacity proves useful in handling conflict. ${ }^{[18,19]}$ To manage conflict effectively, an individual must be able to understand individual differences, ${ }^{[18]}$ which may mean that a higher level of emotional capacity enhances an individual's conflict management styles. ${ }^{[20]}$ Au et al. (2010) argue that researching the relationship between emotional capacity and conflict management is one way of gaining insight into how people handle different situations through their various conflict management styles. ${ }^{[21]}$

There are few studies that illustrate whether and how often RNs actually possess skills in conflict management, and there are also few studies that describe the various strategies that RNs use to handle conflict. As mentioned, RNs predomi- nantly use an integrating conflict management style, which can be interpreted as constructive conflict management in that it might indicate awareness of the context. ${ }^{[2,23]}$ As the participants in this study rated their conflict management competence as high, this can be understood as using an integrating conflict management style. This is also confirmed by the fact that RNs who used their expertise in CMC had higher self-reported CMC than those who did not use such competence.

\section{Method discussion}

The great advantage of self-reported questionnaires is that they give a direct picture of the respondents' own views, and provide access to phenomenological data, i.e. respondents' perceptions of themselves and their world, which are otherwise unobtainable. The main disadvantage of self-report is that there are several potential validity problems associated with it. For instance, people are not always truthful. ${ }^{[24]}$ They may deceive themselves (such as when an NSPG cannot admit that she/he has a great deal to learn), or they may deceive the researcher (such as when a young $\mathrm{RN}$ does not want to reveal any thoughts or behaviour she/he may have that are undesirable within the profession). If an $\mathrm{RN}$ rates herself as having a certain knowledge or competence, how do we as researchers know she has applied this knowledge? Furthermore, research participants may not be able to provide the level of detail, or use the concepts, the researcher is interested in. In order to get a clearer picture of students' and registered nurses' actual expertise in conflict we need to add interviews and observations. Based on the results here, it is important to conduct intervention studies to prepare students for the challenges of today's healthcare, not only at the local- and national level, but also at the international level. The authors of this article are aware that the difference in sample size ( $\mathrm{n}$ $=569 ; n=227$ ) could be a problem since sums of squares require a different formula. However, we used the statistical software SPSS, which automatically uses the right formula, indicating that the unequal sample size did not affect the result.

\section{CONCluding REMARKS}

Experience of international studies during nursing education, or long professional experience, resulted in higher selfreported conflict management competence (CMC). Hence, the CMC items in the NPC Scale can be used for identifying self-reported conflict management competence among NSPGs and RNs.

\section{CONFLiCTS OF INTEREST Disclosure}

The authors declare that that they have no conflicting interests. 


\section{REFERENCES}

[1] Kantek F, Kavla I. Nurse-nurse manager conflict: how do nurse managers manage it? Health Care Manag (Frederick). 2007; 26(2): 147-51. http://dx.doi.org/10.1097/01.hcm.0000268618.3 3491.84

[2] Brinkert R. A literature review of conflict communication causes, costs, benefits and interventions in nursing. J Nurs Manag. 2010; 18(2): 145-56. PMid:20465742 http://dx.doi.org/10.1111/j $.1365-2834.2010 .01061 . x$

[3] Bagshaw D, et al. Bridging the fields of drama and conflict management. In: DRACON International: Empowering students to handle conflicts through school based programmes. Malmö: MUEP (Malmö University Electronic Publishing); 2007.

[4] Theisen JL, Sandau KE. Competency of new graduate nurses: a review of their weaknesses and strategies for success. J Contin Educ Nurs. 2013; 44(9): 406-14. PMid:23799789 http: //dx.doi .org /10.3928/00220124-20130617-38

[5] Rahim M. Toward a theory of managing organizational conflict. The International Journal of Conflict Management. 2002; 13(3): 2016-35.

[6] Johansen M. Keeping the peace: Conflict management strategies for nurse managers. Nursing Management. 2012; 2(43). http: //dx.doi.org/10.1097/01.numa.0000410920.90831.96

[7] de Wit FR, Greer LL, Jehn KA. The paradox of intragroup conflict: a meta-analysis. J Appl Psychol. 2012; 97(2): 360-90. PMid:21842974 http://dx.doi.org/10.1037/a0024844

[8] Pines EW, et al. Stress resiliency, psychological empowerment and conflict management styles among baccalaureate nursing students. J Adv Nurs. 2012; 68(7): 1482-93. PMid:22092499 http: //dx.doi.org/10.1111/j.1365-2648.2011.05875.x

[9] Ogunyemi D, et al. Conflict styles in a cohort of graduate medical education administrators, residents, and board-certified physicians. J Grad Med Educ. 2011; 3(2): 176-81. PMid:22655139 http://dx.doi.org/10.4300/JGME-D-10-00184.1

[10] Pines EW, et al. Enhancing resilience, empowerment, and conflict management among baccalaureate students: outcomes of a pilot study. Nurse Educ. 2014; 39(2): 85-90. PMid:24535184 http: //dx.doi.org/10.1097/NNE.0000000000000023

[11] Sportsman SP, Hamilton. Conflict management styles in the health professions. J Prof Nurs. 2007; 23(3): 157-66. PMid:17540319 http://dx.doi.org/10.1016/j.profnurs.2007.01.010

[12] Thomas K, Kilmann R. Thomas-Kilmann Conflict Mode Instrument. Monutain View, CA: CPP, Inc; 2007. PMid:21631788

[13] Pearson A, et al. Comprehensive systematic review of evidence on developing and sustaining nursing leadership that fosters a healthy work environment in healthcare. Int J Evid Based Healthc. 2007; 5(2): 208-53.

[14] Nilsson J, et al. Development and validation of a new tool measuring nurses self-reported professional competence-the nurse professional competence (NPC) Scale. Nurse Educ Today. 2014; 34(4): 574-80.

[15] Lag (2003:460) om etikprövning av forskning som avser människor. Utbildningsdepartementet, Stockholm, 2004. [The Swedish Act on the Ethical Review of Research Involving Humans, Ministry of Education and Research. Stockholm, 2004]. Available from: http: //www.notisum.se/rnp/sls/lag/20030460.htm

[16] Nilsson J, Carlsson M, Johansson E, et al. Nursing in a globalized world: Nursing students with international study experience report higher competence at graduation. Open Journal of Nursing. 2014; 4: 848-58. http://dx.doi.org/10.4236/ojn. 2014.412090

[17] Button L, et al. The impact of international placements on nurses' personal and professional lives: literature review. J Adv Nurs. 2005; 50(3): 315-24. PMid:15811111 http://dx.doi.org/10.1111/j $.1365-2648.2005 .03395 . x$

[18] Goleman D. The emotionally competent leader. Healthc Forum J. 1998; 41(2): 36, 38, 76. PMid: 10177113

[19] Jordan PJ, Troth AC. Emotional intelligence and conflict resolution in nursing. Contemp Nurse. 2002; 13(1): 94-100. PMid:16118974 http://dx.doi.org/10.5172/conu.13.1.94

[20] Morrison J. The relationship between emotional intelligence competencies and preferred conflict-handling styles. J Nurs Manag. 2008; 16(8): 974-83. PMid:19094110 http://dx.doi.org/10.1111/j $.1365-2834.2008 .00876 . x$

[21] Au A, et al. The Coping with Caregiving Group Program for Chinese caregivers of patients with Alzheimer's disease in Hong Kong. Patient Educ Couns. 2010; 78(2): 256-60. PMid:19619974 http://dx.doi.org/10.1016/j.pec.2009.06.005

[22] Al-Hamdan Z, Shukri R, Anthony D. Conflict management styles used by nurse managers in the Sultanate of Oman. J Clin Nurs. 2011; 20(3-4): 571-80. PMid:21219529 http://dx.doi.org/10.1111 /j.1365-2702.2010.03557.x

[23] Chan JC, Sit EN, Lau WM. Conflict management styles, emotional intelligence and implicit theories of personality of nursing students: a cross-sectional study. Nurse Educ Today. 2014; 34(6): 934-9. PMid:24225346 http://dx.doi.org/10.1016/j.nedt. 2013.10.012

[24] Noben CY, et al. Quality appraisal of generic self-reported instruments measuring health-related productivity changes: a systematic review. BMC Public Health. 2014; 14: 115. PMid:24495301 http://dx.doi.org/10.1186/1471-2458-14-115 